\title{
Finish drying and surface sterilization of bay leaves by microwaves
}

\author{
Kapoor, A.; Sutar, P. P. * \\ a Department of Food Process Engineering, National Institute of Technology Rourkela, Odisha, India \\ *E-mail of the corresponding author: sutarp@nitrkl.ac.in
}

\begin{abstract}
Bay leaves (Laurus nobilis L.) refers to aromatic leaves which are native to minor regions of Asia. In order to extend the shelf life of the bay leaves its water activity and the surface micro-organisms were reduced using microwave heating at different power densities in the range 32.14 to 142.85 $\mathrm{Wg}^{-1}$. Treatment time at each power level was maintained constant at $150 \mathrm{~s}$. The maximum reduction in water activity and moisture content occurred at highest power density. The heating time-temperature profile was obtained at all power levels. TPC, color change and browning index (BI) of bay leaves were measured in order to determine the effect of microwave treatment on microbial reduction and quality. The highest reduction in TPC was found in leaves heated at $142.85 \mathrm{Wg}^{-1}$ power density along with acceptable quality parameters of the treated bay leaves.
\end{abstract}

Keywords: Bay leaves; Microwave heating; TPC; Colour change. 


\section{Introduction}

Bay leaves hail from the bay tree and originally belongs to the family Lauraceae which is scientifically known as Laurus nobilis. It is believed to have been originated in Asia minor region, from where it is distributed to all over Mediterranean region and other parts of Asia. Bay leaves began to find its medicinal use during the European Middle Ages. Bay leaves belonging to various different origins were studied by different researchers for its chemical composition. In almost all the cases, 1,8-cineole was found to be the major component with percentages ranging between $31.4 \%$ and 56\% [1,2]. Other compounds that are also present in appreciable amount include trans-sabinene hydrate, linalool, a-terpinyl-acetate, sabinene, methyl eugenol and eugenol [3]. The various benzene compounds like eugenol, methyl eugenol and elemicin, present in bay leaves with percentages ranging between $1 \%$ and $12 \%$. These compounds are responsible for the sensory qualities of bay leaves [4]. The essential oil content of bay leaves varies with the source of origin of the bay leaves and it is different for bay leaves obtained from different resources. Generally, the essential oil content of bay leaves ranges from $1 \%$ to $3 \%$ on a fresh weight basis. Bay leaves have a strong aroma but are also quite bitter. The bitterness of bay leaves can be reduced to an acceptable extent by drying. Thus the essential oils in dried bay leaves contribute to a strong, spicy aroma and are widely used throughout the world as a flavor enhancer in varieties of foods. Being one of the best-known flavoring leaves all over the world, they find their use in soups, sauce, sausages, stews, pickles and also act as an essential ingredient of the herb mixes. As a medicinal plant, bay leaves have been used as a cure for rheumatism, earaches and skin rashes. In addition, it has been also employed as a stomatic, carminative, astringent, stimulatory, emetic, emmenagogic, diaphoretic, abortifacient agent, and as an insect repellent. Essential oil obtained from bay leaves has also found its use in the cosmetic industry. Micro-organisms exist in the dried bay leaves which affects the shelf life. In order to extend the shelf life of the bay leaves its water activity must be decreased and the microbes present in the surface must be inactivated. Thus, it requires finished drying and surface sterilization. Recently, microwave heating has gained popularity due to its various advantages like quick and uniform heating, high-temperature short time treatment, inactivation of microbes without much damage to food quality [5]. Considering all the above reviews, this study aims to carry out microwave finish drying and surface sterilization of bay leaves. 


\section{Materials and Methods}

\subsection{Raw materials}

The bay leaves were collected from the local market of Rourkela, Odisha, India. The samples collected were stored in a refrigerator $\left(4^{\circ} \mathrm{C}\right)$ until usage to prevent any type of quality deterioration in the product.

\subsection{Determination of moisture and water activity}

Moisture content and the water activity were determined for both the control untreated samples and the microwave treated samples. For determination of the moisture content, vacuum oven method was used. The water activity of the conditioned sample was measured using water activity meter (Rotronic, HC2-AW, Rotronic measurement solution, Switzerland) at initial temperature $20.02{ }^{\circ} \mathrm{C}$ and relative humidity $53 \%$.

\subsection{Microwave finish drying}

\subsubsection{Experimental Setup}

Finished drying and surface sterilization of the bay leaves were carried out in a microwave oven. A programmable domestic microwave oven (Samsung, Model-CE73JD) with a maximum output of $800 \mathrm{~W}$ at $2450 \mathrm{MHz}$ was used for the experiments. The dimensions of the microwave cavity were $310 \mathrm{~mm}$ width, $290 \mathrm{~mm}$ height, and $220 \mathrm{~mm}$ depth. The oven was fitted with a fan, a glass turntable (30 cm diameter) and a digital controller to adjust the pulsation of microwave power and total heating time. Schematic diagram of the microwave heating system is shown in Fig. 1. The efficiency of the microwave oven was calculated according to USFDA (United State Food and Drug Administration) procedure at different power levels and the average efficiency was determined. The heat absorbed by water (220 g) was equated to the input energy[6]. During the drying process, the microwave oven was operated at five different power densities 32.14, 53.57, 80.35, 107.14 and $142.85 \mathrm{Wg}^{-1}$ and a constant treatment time was maintained at $150 \mathrm{~s}$. The surface temperature of the bay leaves was regularly measured at an interval of $10 \mathrm{~s}$ using infrared sensor (IRL380KUSAM MECO, India) up to 150 seconds at each power density. For accuracy in results, the temperature was measured at three different points each time and its average was taken as the final temperature. 


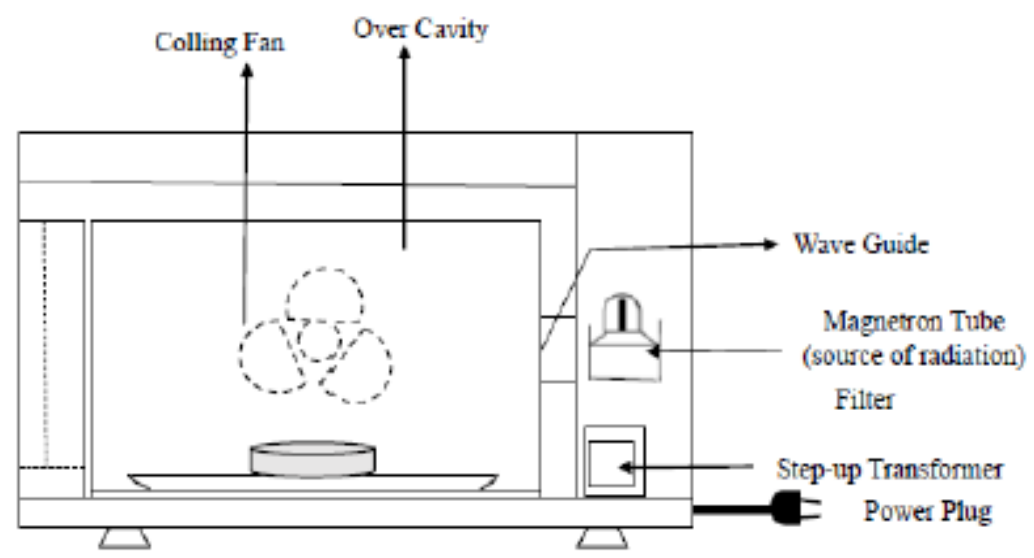

Figure 1. Schematic diagram of the microwave heating system

\subsection{Microbial analysis}

Microbial analysis was performed on the bay leaves in order to find the effect of microwave treatment on the reduction of microbial contamination. In this regard, the Total Plate Count (TPC) per gram was done both for the control sample and the final samples treated at different microwave power densities.

\subsubsection{Culture Preparation}

Firstly, the culture media was prepared by mixing $28 \mathrm{~g}$ of nutrient agar with $1000 \mathrm{~mL}$ of distilled water. It was then properly mixed with help of a stirrer and heated up to $60^{\circ} \mathrm{C}$ for proper dissolution of the nutrient agar in the distilled water. Media was then transferred to the glass bottles leaving some headspace at the top. Glass bottles were autoclaved at 15 psi at $121^{\circ} \mathrm{C}$ for 15 minutes. After completion of the autoclave heating, the media was allowed to cool below $50^{\circ} \mathrm{C}$. The media was then poured into pre-sterilized Petri dishes such that a uniform layer of culture (2-3 mm) was obtained. The whole pouring process of the culture media was carried out under laminar flow hood in order to prevent any kind of contamination.

\subsection{Color analysis}

The color of the fresh and treated bay leaves was measured by scanning them with help of HP scanner. The scanned samples were then analyzed with help of Adobe Photoshop software. The color value of samples was measured at three different points for accuracy and expressed as L (whiteness or brightness/darkness), a (redness/ greenness) and b (yellowness/ blueness) at any time, respectively. The total color change $(\Delta \mathrm{E})$ indicates the overall color change and quantification was done using the equation given below [7]: 


$$
\Delta E=\left[\left(L-L^{*}\right)^{2}+\left(a-a^{*}\right)^{2}+\left(b-b^{*}\right)^{2}\right]^{0.5}
$$

where $L, a$, and $b$ are respective values measured during high power short time microwave finish drying. The $L^{*}, a^{*}$, and $b^{*}$ are values of the fresh sample (before microwave finish drying).The browning index $(B I)$ were calculated from $\mathrm{L}, \mathrm{a}, \mathrm{b}$ values and used to describe the brown color produced due to heat accumulation during the decontamination process. The equation to calculate $B I$ is given below:

$$
B I=[100(x-0.31)] / 0.17
$$

Where

$$
x=(a+1.75 L) /(5.645 L+a-3.012 b)
$$

\section{Results and Discussion}

\subsection{Effect of power density on moisture content and water activity}

The moisture content and the water activity was measured for both the control and treated samples. The results obtained showed that the average initial moisture content of bay leaves was $10.68 \%(\mathrm{wb})$ which was reduced up to safe moisture content. The maximum reduction in the moisture level occurred when bay leaves were treated at the power density of $142.85 \mathrm{Wg}^{-1}$. In this case, final moisture content obtained was $1.24 \%$ (wb). Similar trends were obtained for the water activity of bay leaves; initial average water activity of bay leaves was measured to be 0.89 . The maximum reduction in the water activity occurred at $142.85 \mathrm{Wg}^{-1}$ and reached to 0.18 . Table 1 gives the moisture content and the water activity for bay leaves treated at different power densities.

Table 1. Final moisture content, water activity and TPC log reduction in the microwave treated bay leaves

\begin{tabular}{llllll}
\hline $\begin{array}{l}\text { Power } \\
\text { Density } \\
\left(\mathbf{W ~ g ~}^{-1}\right)\end{array}$ & $\begin{array}{l}\text { Final } \\
\text { Moisture } \\
\text { Content } \\
\text { (\%, wb) }\end{array}$ & $\begin{array}{l}\text { Water } \\
\text { activity }\end{array}$ & $\begin{array}{l}\text { Log } \\
\text { Reduction }\end{array}$ & $\boldsymbol{\Delta E}$ & BI \\
\hline 32.14 & 2.23 & 0.41 & 0.115 & 0.58 & 49.90 \\
53.57 & 1.87 & 0.35 & 0.291 & 0.65 & 55.78 \\
80.35 & 1.75 & 0.27 & 0.532 & 1.20 & 58.92 \\
107.14 & 1.66 & 0.23 & 0.780 & 1.39 & 63.59 \\
142.85 & 1.24 & 0.18 & 1.069 & 1.62 & 69.92 \\
\hline
\end{tabular}




\subsection{Effect of microwave power density on product temperature and microorganisms}

Bay leaves samples were treated for 150 seconds at each of the five microwave power densities. The surface temperature of the bay leaves was measured regularly during the microwave treatment of bay leaves. The time-temperature profile obtained at different power densities showed that maximum surface temperature reached was $101.6^{\circ} \mathrm{C}$ in the case when bay leaves were treated at $142.85 \mathrm{Wg}^{-1}$ for $150 \mathrm{~s}$. While minimum surface temperature reached was $75.85^{\circ} \mathrm{C}$ when bay leaves were treated at $32.14 \mathrm{Wg}^{-1}$ for $150 \mathrm{~s}$. Total plate count (TPC) was done for both control and microwave treated samples of bay leaves. Results showed that plate count was minimum for the sample treated at $142.85 \mathrm{Wg}^{-1}$. While the treatment at $32.14 \mathrm{Wg}^{-1}$ obtained a maximum number of plate counts. Total log reduction was also calculated for samples treated at different power densities and it ranged from 0.115 to 1.069 . The log reduction at different power densities is given in Table 1.

\subsection{Effect of microwave power density on color change and browning index}

Color analysis was performed to determine the color change $(\Delta E)$ which was encountered during the microwave treatment of the bay leaves. Browning Index (BI) was also calculated for both initial and the microwave treated samples. Results obtained showed that maximum color change of 1.62 was obtained when the sample was treated at $142.85 \mathrm{Wg}^{-1}$. Similar results were obtained for Browning Index (BI) that is a maximum BI value of 69.92 was obtained for microwave treatment at $142.85 \mathrm{Wg}^{-1}$.

\section{Conclusions}

Maximum water activity reduction from 0.89 to 0.18 occurred at $142.85 \mathrm{Wg}^{-1}$ power density. Microbial analysis was performed in order to determine the effect of microwave treatment on microbial reduction of bay leaves. TPC was obtained for fresh as well as microwave treated samples. Maximum log reduction (1.069) was achieved in the sample treated at $142.85 \mathrm{Wg}^{-1}$ power density for 150 seconds. The color change was also quantified and the Browning Index (BI) was measured which indicated the less effect of microwave treatment on the color of the product. It can be concluded from the results that high power density short time microwave finish drying turns out to be an effective alternative for drying and surface sterilization of bay leaves with acceptable quality parameters.

\section{Acknowledgements}

The authors are thankful to Ministry of Food Processing Industries (MoFPI), Government of India for their financial support to this research work. 


\section{References}

[1] Doymaz, I; Pala, M. Hot-air drying characteristics of red pepper. Journal of Food Engineering 2002, 55, 331-335.

[2] Drouzas, A.E; Tsami E; Saravacos, G.D. Microwave/ vacuum drying of model fruit gels. Journal of Food Engineering 1999, 39, 117-122.

[3] Demir, V; Gunhan, T; Yagcioglu, A.K; Degirmencioglu, A. Mathematical modelling and the determination of some quality parameters of air-dried bay leaves. Biosystems Engineering 2004, 88, 325-335.

[4] Feng, H. Analysis of microwave assisted fluidized-bed drying of particulate product with a simplified heat and mass transfer model. International Communications in Heat and Mass Transfer 2002, 29, 1021-1028.

[5] Shirkole S. S. and Sutar P.P. High power short time microwave finish drying of paprika (Capsicum annuum L.): development of models for moisture diffusion and color degradation. Drying Technology 2018, DOI:10.1080/07373937.2018.1454941

[6] USFDA. United State Food and Drug Administration. HEW publication (FDA), Rockville, Maryland, Montgomerypp, Procedure for field testing microwave oven, 1977, pp 13

[7] Behera G, Sutar PP, Aditya S. Development of novel high power-short time (HPST) microwave assisted commercial decontamination process for dried turmeric powder (Curcuma Longa L.). Journal of Food Science and Technology. 2017 Nov 1;54(12):4078-91. 